\title{
From quantum chemical formation free energies to evaporation rates
}

\author{
I. K. Ortega ${ }^{1}$, O. Kupiainen ${ }^{1}$, T. Kurtén ${ }^{1}$, T. Olenius ${ }^{1}$, O. Wilkman ${ }^{2}$, M. J. McGrath ${ }^{3}$, V. Loukonen ${ }^{1}$, and \\ H. Vehkamäki ${ }^{1}$ \\ ${ }^{1}$ Division of Atmospheric Sciences, Department of Physics, P.O. Box 64, 00014 University of Helsinki, Finland \\ ${ }^{2}$ Division of Geophysics and Astronomy, Department of Physics, P.O. Box 64, 00014 University of Helsinki, Finland \\ ${ }^{3}$ Department of Biophysics, Graduate School of Science, Kyoto University, Kyoto 606-8502, Japan
}

Correspondence to: I. K. Ortega (ismael.ortegacolomer@helsinki.fi)

Received: 22 August 2011 - Published in Atmos. Chem. Phys. Discuss.: 5 October 2011

Revised: 5 December 2011 - Accepted: 8 December 2011 - Published: 4 January 2012

\begin{abstract}
Atmospheric new particle formation is an important source of atmospheric aerosols. Large efforts have been made during the past few years to identify which molecules are behind this phenomenon, but the actual birth mechanism of the particles is not yet well known. Quantum chemical calculations have proven to be a powerful tool to gain new insights into the very first steps of particle formation. In the present study we use formation free energies calculated by quantum chemical methods to estimate the evaporation rates of species from sulfuric acid clusters containing ammonia or dimethylamine. We have found that dimethylamine forms much more stable clusters with sulphuric acid than ammonia does. On the other hand, the existence of a very deep local minimum for clusters with two sulfuric acid molecules and two dimethylamine molecules hinders their growth to larger clusters. These results indicate that other compounds may be needed to make clusters grow to larger sizes (containing more than three sulfuric acid molecules).
\end{abstract}

\section{Introduction}

Climate change is one of the central scientific issues in the modern world. While the effects of long-lived greenhouse gases are fairly well known, the radiative forcing associated with atmospheric aerosols is still very uncertain (Baker and Peter, 2008). According to the Intergovernmental Panel on Climate Change (IPCC, 2007), aerosols remain the dominant uncertainty in predicting radiative forcing and climate change. Atmospheric aerosols also have adverse effects on human health and deteriorate visibility (Nel, 2005; Pope and Dockery, 2006).
An important fraction of atmospheric particles are formed from condensable vapours by gas-to-particle transformation (Spracklen et al., 2008; Merikanto et al., 2009; Kazil et al., 2010). While new-particle formation is observed everywhere in the Earth's atmosphere (Kulmala et al., 2004), the actual birth mechanism of particles is still uncertain. In terms of the molecular species participating in nucleation, the only thing known for certain is that sulfuric acid is somehow involved (Kuang et al., 2008; Sihto et al., 2006). On the other hand, sulfuric acid alone cannot explain the observed particle formation rate, and several other candidates, both organic and inorganic, have been proposed. Base molecules like ammonia and especially amines are one of the strongest candidates to be relevant in atmospheric nucleation; consequently, they have been the focus of numerous studies in recent years (Kurtén et al., 2008; Loukonen et al., 2010; Nadykto et al., 2011; Ge et al., 2011, 2011a).

Historically, the main problem in understanding how particles form was the lack of experimental methods with enough sensitivity to follow the very first steps of particle formation. Recently, the development of "state of the art" instruments (Junninen at al., 2010) has allowed researchers, for the first time, to measure molecular clusters relevant for nucleation. Unfortunately, these experimental methods are only able to measure charged particles. Given that charged particles most likely only account for about $10 \%$ of new formed particles (Kulmala et al., 2007), the combination of experiments on charged clusters and theoretical methods able to provide information on neutral clusters is urgently needed for a complete understanding of atmospheric nucleation. Several theoretical methods have been used in attempt to describe the first steps of particle formation. One of the most successful of these methods has been quantum chemical calculations 
(Kurtén and Vehkamäki, 2008; Nadykto et al., 2008, and references therein). Quantum chemical calculations are normally used to calculate the formation free energy of different clusters. These formation free energies can give us an idea of the relative stability of the clusters, but to compare them directly with experimental results, we need to include kinetics. This can be done through simple kinetic codes (see, for example, McGrath et al. (2011) and references therein), but if we want to include quantum chemical results in these codes, the formation free energies first need to be converted into cluster evaporation rates.

The present work can be divided into two stages. In the first stage, we test six different quantum chemical methods to obtain the formation free energies of a series of small sulfuric acid clusters containing ammonia or dimethylamine (DMA) as the second molecule. Comparing these methods with high level ones, we choose the method with the best accuracy at a reasonable computational cost. In the second stage, we extend our calculation up to clusters containing four sulfuric acid molecules and four base molecules (ammonia or DMA). Using the calculated Gibbs free energies of formation, we compute the evaporation rates of component species from these clusters. We then compare the calculated evaporation rates of ammonia and DMA clusters to determine their importance in atmospheric particle formation.

\section{Methodology}

\subsection{Evaporation rates}

According to the law of mass balance, for a cluster forming reaction:

$i+j \rightarrow(i+j)$

where $i$ and $j$ can be isolated molecules or clusters of molecules, we can write the equilibrium constant as:

$$
\frac{\left(C_{i+j}^{\mathrm{eq}}\right)}{\left(C_{i}^{\mathrm{eq}}\right)\left(C_{j}^{\mathrm{eq}}\right)}=c_{\mathrm{ref}}^{-1} \exp ^{\left(\frac{-\Delta G}{k T}\right)}
$$

where $C_{x}^{\mathrm{eq}}$ are the equilibrium concentration of different compounds present in the reaction $(i, j$ and $l+j) k$ is the Boltzmann constant, $T$ is the temperature and $\Delta G$ is the Gibbs free energy of the reaction at temperature $T$ and reference pressure $c_{\text {ref }}$.

Assuming equilibrium and detailed balance, cluster formation must be equal to cluster destruction (evaporation):

$\gamma_{i}(i+j) C_{i+j}=\beta_{i j} C_{i} C_{j}$

where $\gamma_{i}(\mathrm{i}+\mathrm{j})$ is the evaporation rate of $i$ from $i+j$ and $\beta_{i j}$ the collision rate of $i$ with $i+j$, combining Eqs. (1) and (2) we can get an expression for the evaporation rate of $i\left(\gamma_{i}\right)$ from the cluster $i+j$ that relates it with the Gibbs free energy of formation:

$\gamma_{i}(i+j)=\beta_{i j} c_{\text {ref }} \exp \left(\frac{\Delta G(i+j)-\Delta G(i)-\Delta G(j)}{k T}\right)$

where $\Delta G(i+j), \Delta G(i)$ and $\Delta G(j)$, are the Gibbs free energies of formation of clusters $i+j, i$ and $j$ from monomers at reference pressure $c_{\text {ref. }}$. It must be noted that $c_{\text {ref }}$ will cancel out from the evaporation rate. In the case where $i$ and/or $j$ are monomers, $\Delta G(i)$ and/or $\Delta G(j)$ are zero.

The collision rate $\beta_{i}$ is given by kinetic gas theory as (Friedlander 1977; Chapman and Cowling 1970):

$\beta_{i j}=\left(\frac{3}{4 \pi}\right)^{1 / 6}\left(\frac{6 k T}{m_{j}}+\frac{6 k T}{m_{j}}\right)^{1 / 2}\left(\left[V_{j}\right]^{1 / 3}+\left[V_{i}\right]^{1 / 3}\right)^{2}$

where $m_{i}$ and $m_{j}$ are the masses of $i$ and $j$ and $V_{j}$ and $V_{i}$ are their respective volumes. When two particles collide to form a larger cluster, they acquire an excess energy that needs to be dissipated. If this energy is not dissipated fast enough the cluster will break apart. In other words, if this energy nonaccommodation is relevant, not all the collisions will lead to cluster formation events. Kurtén et al. (2010), however, showed that this is probably not a major effect in sulfuric acid clustering, and therefore we assume here that all collisions will lead to the formation of a cluster (i.e., the sticking factor is one). Energy non-accommodation is not the only factor affecting the sticking factor, as activation energies and steric hindrance can also be an issue. Since the cluster formation does not exhibit any kinetic barrier, it is very unlikely that activation energies have any effect in the present work. Steric hindrance can have some effect in the case of collisions with DMA molecules or DMA - containing clusters, since the molecule contains two methyl groups which do not participate in hydrogen bonding. The effect of this on the overall sticking factor is likely to be small for clusters with a small number of DMA molecules compared to the number of sulfuric acid molecules. For clusters with the same amount of DMA and sulfuric acid molecules, the steric hindrance may be higher. In the case of clusters containing more DMA than sulfuric acid molecules, the steric hindrance may become an important issue. In any case, clusters containing more DMA than sulfuric acid molecules are not thermodynamically stable, so the error associated with assuming a sticking factor of one for all clusters will likely be smaller than the error associated with the calculation of formation free energies.

Volumes $V_{j}$ and $V_{i}$ can be calculated using the clusters densities and atomic masses of $i$ and $j$. In the present study, we have used the bulk liquid density as an approximation for the density of a pure cluster (formed only by molecules of one compound) or a molecule. In the case of cluster formed by different compounds we need to determine the density to be used.

In order to test the sensivity of the calculated collision rates to the method used to calculate the density, we have 
tested four approximations and applied them to four different clusters. These approximations are: (1) consider unit density for all clusters $\left(1000 \mathrm{~kg} / \mathrm{m}^{-3}\right)$, (2) consider the density of a mixed cluster to be the liquid density of bulk sulfuric acid, (3) consider the density as a weighted average of the liquid bulk densities of different molecules forming the clusters and (4) assume an ideal solution in which partial molecular volumes of each substance are independent of the liquid composition. The density is then simply calculated from the total mass and density of the cluster.

As can be seen from Table 1 the collision rates are quite insensitive to the assumption used for cluster density. Even when using the simple approximation of a unit density for all clusters, the calculated collision rates are quite close to those calculated with more exact methods. We consider the fourth approach proposed to be the most accurate, and it is unlikely that any more exact method will dramatically improve the results.

Once we choose the method to calculate collision coefficients, we can turn to the computationally more demanding portion of determining the evaporation rate: The formation free energies of different clusters. Experimental formation free energies are seldom available, and they are usually limited to charged systems (for example Lovejoy et al., 2004.). Different theoretical approaches can be used to obtain the desired formation free energies. Quantum chemical calculations represent the most accurate method, but require extremely large amounts of computer time even for approximate methods and modest cluster sizes. Evaporation rates depend exponentially on formation free energies, which means the accuracy of these calculations is very important. High-level quantum mechanical calculations can be used to obtain quantitative formation free energies for different clusters. Unfortunately, these methods are so demanding that they can only be applied to very small clusters (a few molecules). Since we are interested in obtaining formation free energies for as large clusters as possible, we need to look for methods that can yield good formation energies with reasonable computational costs. Multi-step methods combining different levels of theory (Ortega et al., 2008) have been successfully applied to relatively large systems. Therefore we have tested a total of six different multi-step procedures.

\subsection{Quantum Chemical calculations}

We tested a selection of parameterized multi-step methods available with the Gaussian 09 program suite (Frisch et al., 2009), a method used previously by our group (Ortega et al., 2008), and a new combination developed specifically for this work. In general, the methods available for Gaussian09 were developed with the goal of calculating molecular energies within chemical accuracy. They combine calculations at different levels of theory, calculating minimum-energy geometries and frequencies at lower levels (as these steps require multiple energy evaluations, as well as the more expensive computation of first and second derivatives with respect to the nuclear co-ordinates), followed by one or more high-level single-point energy calculations. Extra corrections are added to the calculated energies to account for basis set size effects, core electron correlation, etc. There are different families of multi-step methods available, involving different sets of methods and fitted parameters.

\subsection{CBS-n family}

The main characteristic of these methods is that they employ nonlinear pair natural orbital extrapolations to the complete basis set limit. We have used two methods from this family, CBS-QB3 (Montgomery et al., 1999) and CBS-4M (Montgomery et al., 2000). The main difference between these methods is the level used for geometry and frequencies calculation. CBS-QB3 uses B3LYP/CBSB7 while CBS-4M uses $\mathrm{UHF} / 3-21 \mathrm{G}^{*}$.

\subsection{Gn family}

We have chosen two methods from this family: G3MP2B3 (Baboul et al., 1999) and G4MP2 (Curtiss et al., 2007). Both have removed the MP3 and MP4 single point calculations with large basis sets from the original G3 and G4 methods to reduce the computational cost. Both of these methods calculate geometries and frequencies with the B3LYP density functional, but use different basis set; G3MP2B3 uses 6-31G(d) while G4MP2 uses 6-31G(2df,p).

\subsection{Locally developed methods}

The multi-step method used previously in our group (Ortega et al 2008) combines BLYP/DZP optimized geometries and frequency calculations with RI-CC2/aug-cc-pV(T+d)Z (Hättig et al., 2000, Dunning Jr. et al. 2001) single point energy calculations using TURBOMOLE (Ahlrichs et al., 1989). The new method investigated for its appropriateness for atmospheric cluster systems is a multi-step method combining B3LYP/CBSB7 optimized geometry and frequency calculations with RI-CC2/ aug-cc-pV(T+d)Z single point energy calculations. We will refer to the former method as Ortega et al. (2008) and the latter as B3RICC2. The difference between these two methods lies only in the calculation of the optimized geometries and frequencies.

Additionally, we have used a combination of high-level quantum chemical methods (the most accurate approach possible given the constraints of current computer hardware; see the supplementary information for a detailed description) to compute the formation free energy of the sulfuric acid dimer. This calculation will serve as the reference calculation to evaluate the accuracy of the other methods. Due to the exceedingly high computational cost and poor scalability of the methods used, it is not currently feasible to apply it to larger clusters. 
Table 1. Collision rate (units of $1 \mathrm{~s}^{-1}$ ) of sulfuric acid with base containing clusters for different methods of estimating the cluster density.

\begin{tabular}{lcccc}
\hline Cluster & $\begin{array}{c}\text { Method 1 } \\
\text { (unit density) }\end{array}$ & $\begin{array}{c}\text { Method 2 } \\
\text { (Sulfuric acid density for all) }\end{array}$ & $\begin{array}{c}\text { Method 3 } \\
\text { (weighted average) }\end{array}$ & $\begin{array}{c}\text { Method 4 } \\
\text { (ideal solution) }\end{array}$ \\
\hline $\mathrm{H}_{2} \mathrm{SO}_{4} \times\left(\mathrm{CH}_{3}\right)_{2} \mathrm{NH}$ & $5.4 \times 10^{-10}$ & $3.6 \times 10^{-10}$ & $4.1 \times 10^{-10}$ & $4.2 \times 10^{-10}$ \\
$\mathrm{H}_{2} \mathrm{SO}_{4} \times \mathrm{NH}_{3}$ & $5.2 \times 10^{-10}$ & $3.5 \times 10^{-10}$ & $4.0 \times 10^{-10}$ & $3.8 \times 10^{-10}$ \\
$\left(\left(\mathrm{CH}_{3}\right)_{2} \mathrm{NH}\right)_{2}$ & $5.1 \times 10^{-10}$ & $3.4 \times 10^{-10}$ & $4.9 \times 10^{-10}$ & $4.9 \times 10^{-10}$ \\
$\left(\mathrm{NH}_{3}\right)_{2}$ & $5.2 \times 10^{-10}$ & $3.5 \times 10^{-10}$ & $4.7 \times 10^{-10}$ & $4.7 \times 10^{-10}$ \\
\hline
\end{tabular}

\subsection{Conformational sampling}

One major difficulty faced with finding the global minimum structures is conformational sampling. As the cluster size increases, the number of possible arrangements increases quite dramatically, and it can be difficult to exhaustively search this configurational space manually. Therefore, a series of FORTRAN95 codes were written to generate likely candidates for cluster configurations. These codes create large numbers of cluster configurations by inserting molecules at random, such that a distance-based cluster criterion is satisfied. The clusters are checked to see how similar they are to previous clusters (by comparing the relative locations of the center of mass), and too similar clusters are discarded. The energies of all the configurations are computed, and those with the lowest energies are saved. A typical run generates 10000 configurations and saves 50. These saved configurations then undergo a geometry optimization, another similarity test, and a visual inspection to determine which are the best candidates for the full energy/frequency calculations.

The choice of interaction potential for the energy calculations and geometry optimization step is also not a simple one. Because acids and bases are involved, the likelihood of a proton transfer is high. This precludes the use of simple (and fast) empirical potentials. Through the use of the CP2K simulation package (http://cp2k.berlios.de/), we used various semi-empirical wavefunction methods AM1 Dewar et al., 1985, PM3, Stewart, 1989 and PM6 Stewart, 2007, as well as tight-binding self-consistent density functional theory (Cohen et al., 1994). In early tests, it was noticed that tight-binding DFT geometry optimization seemed to give the best structures, so this was used for the bulk of the configurations.

\section{Results}

\subsection{Method benchmark}

Using the methods described above, we have calculated formation free energies and enthalpies from monomers for a small sub-set of the clusters included in this study $\left(\left(\mathrm{H}_{2} \mathrm{SO}_{4}\right)_{n} \bullet\left(\mathrm{NH}_{3}\right)_{m}\right.$, with $n=2-3$ and $\left.m=0-1\right)$. Table 2 summarizes the formation free energy and enthalpies for the different clusters.
The Gibbs free energy of formation of the sulfuric acid dimer calculated with the high level method combination (described in the supplementary material) is $-7.91 \mathrm{kcal} \mathrm{mol}^{-1}$ (Table S-1.6). As can be seen in Table 2, all methods perform relatively well for the sulfuric acid dimer, with CBS-4M and Ortega et al. (2008) having the largest differences compared to the reference formation free energy. The B3RICC2 method gives the best agreement with the high level formation free energy. When we move to larger clusters, the differences between different multi-step methods become evident. B3RICC2 yields quite similar formation free energies to the CBS-QB3 method, which is not surprising since CBS-QB3 uses the same technique for performing the geometry optimization and frequency calculation. In CBS-QB3, frequencies are scaled by 0.99 to account for anharmonicity, while in B3RICC2 we have decided not to use the scaling factor, since it has been derived for isolated molecules and there is no guarantee that it will perform as well for the cluster systems we are interested in. Vibrational anharmonicity thus remains a potentially significant error source, though it is likely to be smaller for these strongly bound acid-base clusters than for e.g. $\mathrm{H}_{2} \mathrm{SO}_{4}-\mathrm{H}_{2} \mathrm{O}$ clusters. Among these four methods, the relatively poor performance of CBS-4M is not surprising, since it uses HartreeFock-level geometries and frequencies, which are not well suited for treating clusters where hydrogen bonds are the main interaction type (Montgomery et al., 2000). CBS-QB3, G4MP2 and G3MP2B3 use B3LYP for optimizing the geometries and calculating the frequencies, which in general should work better than HF for the clusters that we are studying (Lozynski et al., 1998). Since CBS-QB3 includes MP4 corrections and G3MP2B3 and G4MP2 do not, CBS-QB3 should be the best method to use for our system. We extended the calculations for CBS-QB3 and B3RICC2 to larger clusters to check if the good agreement between them continues for larger cluster sizes (Table S-2.1 in the supplementary material). The average difference in the formation free energies between these two methods is $0.74 \mathrm{kcal} \mathrm{mol}^{-1}$, while the computational cost is much smaller for the B3RICC2 method (Fig. S2.1, supplementary material). 
Table 2. Gibbs free energies and enthalpies of formation in $\mathrm{kcal} \mathrm{mol}^{-1}$ for selected sulfuric acid and ammonia clusters obtained with different methods.

\begin{tabular}{lllllllll}
\hline & \multicolumn{2}{c}{ CBS-QB3 } & \multicolumn{2}{c}{ CBS-4M } & \multicolumn{2}{c}{ G4MP2 } & \multicolumn{2}{c}{ G3MP2B3 } \\
cluster & $\Delta \mathrm{H}$ & $\Delta \mathrm{G}$ & $\Delta \mathrm{H}$ & $\Delta \mathrm{G}$ & $\Delta \mathrm{H}$ & $\Delta \mathrm{G}$ & $\Delta \mathrm{H}$ & $\Delta \mathrm{G}$ \\
\hline$\left(\mathrm{H}_{2} \mathrm{SO}_{4}\right)_{2}$ & -18.57 & -8.66 & -15.59 & -5.26 & -17.19 & -7.10 & -17.58 & -7.58 \\
$\left(\mathrm{H}_{2} \mathrm{SO}_{4}\right)_{3}$ & -37.32 & -15.85 & -30.90 & -7.44 & -33.76 & -11.57 & -35.20 & -13.80 \\
$\mathrm{H}_{2} \mathrm{SO}_{4} \bullet \mathrm{NH}_{3}$ & -15.70 & -7.34 & -15.71 & -6.48 & -14.15 & -5.57 & -14.72 & -6.31 \\
$\left(\mathrm{H}_{2} \mathrm{SO}_{4}\right)_{2} \bullet \mathrm{NH}_{3}$ & -45.59 & -24.47 & -42.36 & -19.12 & -41.31 & -19.75 & -42.66 & -21.36 \\
\hline
\end{tabular}

\begin{tabular}{lllll}
\hline \multirow{2}{*}{ cluster } & \multicolumn{2}{c}{ Ortega et al. 2008} & \multicolumn{2}{c}{ B3RICC2 } \\
& $\Delta \mathrm{H}$ & $\Delta \mathrm{G}$ & $\Delta \mathrm{H}$ & $\Delta \mathrm{G}$ \\
\hline$\left(\mathrm{H}_{2} \mathrm{SO}_{4}\right)_{2}$ & -18.51 & -6.00 & -17.85 & -7.89 \\
$\left(\mathrm{H}_{2} \mathrm{SO}_{4}\right)_{3}$ & -36.39 & -8.69 & -35.82 & -14.30 \\
$\mathrm{H}_{2} \mathrm{SO}_{4} \bullet \mathrm{NH}_{3}$ & -15.59 & -5.69 & -16.00 & -7.61 \\
$\left(\mathrm{H}_{2} \mathrm{SO}_{4}\right)_{2} \bullet \mathrm{NH}_{3}$ & -42.91 & -18.08 & -45.00 & -23.82 \\
\hline
\end{tabular}

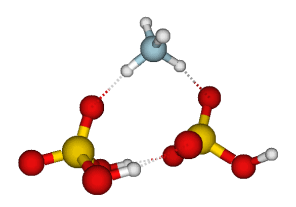

$\mathrm{H}_{2} \mathrm{SO}_{4} \cdot \mathrm{HSO}_{4}^{-} \cdot \mathrm{NH}_{4}^{+}$

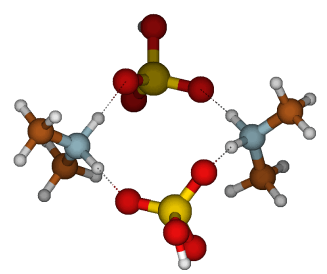

$\left(\mathrm{HSO}_{4}^{-}\right)_{2} \cdot\left(\left(\mathrm{CH}_{3}\right)_{2} \mathrm{NH}_{2}{ }^{+}\right)_{2}$
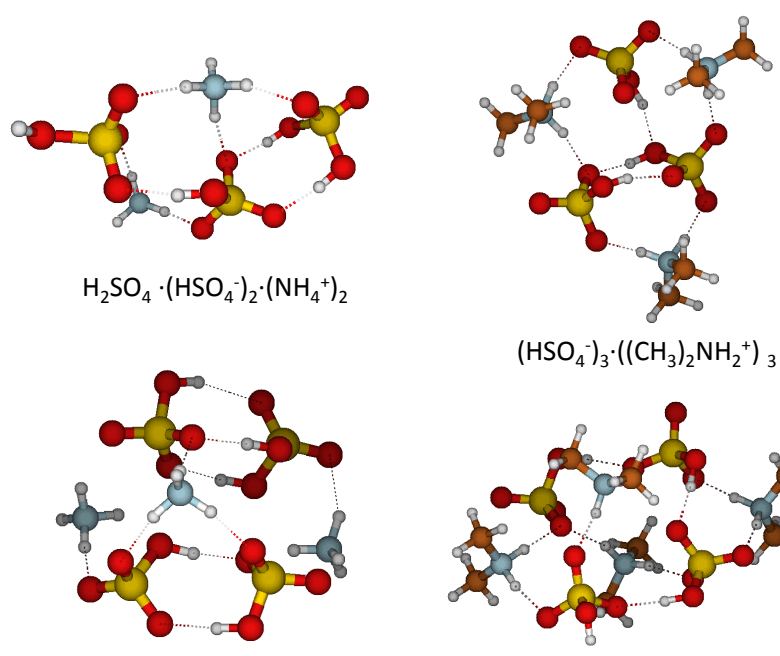

$\mathrm{H}_{2} \mathrm{SO}_{4} \cdot\left(\mathrm{HSO}_{4}^{-}\right)_{3} \cdot\left(\mathrm{NH}_{4}{ }^{+}\right)_{3}$
As a result, we have decided to use the B3RICC2 method to explore larger clusters. We have studied $\left(\mathrm{H}_{2} \mathrm{SO}_{4}\right)_{n} \bullet\left(\mathrm{NH}_{3}\right)_{m}$ and $\left(\mathrm{H}_{2} \mathrm{SO}_{4}\right)_{n} \bullet\left(\left(\mathrm{CH}_{3}\right)_{2} \mathrm{NH}\right)_{m}$ clusters with $n=0-4$ and $m=0-4$.

Figure 1 shows the structures of a selection of the most stable ammonia and DMA clusters found in this study (Cartesian coordinates of all cluster studied can be found in supplementary material (xyz.pdf)). The structures for the most stable conformers found in this work generally agree well with previous works (Kurtén et al., 2008; Loukonen et al., 2010; Nadykto et al., 2011), but in some cases we have found different structures for the most stable conformers than those reported before. When the number of sulfuric acid molecules and bases is small enough, the structure of ammonia and DMA clusters are equivalent. When the numbers of sulfuric acid and base molecules grows, the structures for DMA and ammonia clusters start to differ, since ammonia can form four hydrogen bonds while DMA can only form two. The number of hydrogen bonds is not the only factor that determines the stability of these clusters. The identity of the base is also important. As DMA is a stronger base than ammonia, DMA molecules will interact more strongly with the sulfuric acid molecules. Proton transfers from the acid to the base molecule will also play an important role in stabilizing the cluster, since it leads to the formation of ion pairs, which stabilizes the cluster. In the case of ammonia-containing clusters, at least two sulfuric acid molecules are needed to promote the proton transfer if only one ammonia molecule is present. In clusters where the number of ammonia molecules is larger than the number of sulfuric acid molecules, the extra ammonia molecule is not able to receive a proton from a $\mathrm{HSO}_{4}^{-}$ion (thus forming $\mathrm{SO}_{4}^{2-}$ ) until the cluster contains three sulfuric acid molecules. On the other hand, in DMAcontaining clusters, proton transfer occurs already when just

Fig. 1. The structure of some of the most stable cluster found in this work. Yellow, red, white, blue, and brown spheres represent sulfur, oxygen, hydrogen, nitrogen and carbon atoms, respectively. 
Table 3. Gibbs free energy for the reaction $\left(\mathrm{H}_{2} \mathrm{SO}_{4}\right)_{n-1}$ $\left.\left(\mathrm{NH}_{3} /\left(\mathrm{CH}_{3}\right)_{2} \mathrm{NH}\right)_{m}+\mathrm{H}_{2} \mathrm{SO}_{4} \rightarrow\left(\mathrm{H}_{2} \mathrm{SO}_{4}\right)_{n}\left(\mathrm{NH}_{3} /\left(\mathrm{CH}_{3}\right)_{2} \mathrm{NH}\right)_{m}\right)$ in $\mathrm{kcal} \mathrm{mol}^{-1}$ at $298.15 \mathrm{~K}$.

\begin{tabular}{lcccc}
\hline & \multicolumn{4}{c}{$(\mathrm{m})$ ammonia } \\
\hline Sulfuric acid (n) & 1 & 2 & 3 & 4 \\
\hline 1 & -7.61 & -16.63 & -21.70 & -27.06 \\
2 & -16.21 & -20.89 & -25.25 & -26.11 \\
3 & -10.12 & -16.08 & -25.28 & -28.27 \\
4 & -8.37 & -11.07 & -14.15 & -20.08 \\
\hline
\end{tabular}

(m) DMA

\begin{tabular}{lcccc}
\hline Sulfuric acid (n) & 1 & 2 & 3 & 4 \\
\hline 1 & -15.40 & -23.83 & -30.67 & -33.85 \\
2 & -19.48 & -35.88 & -37.62 & -40.26 \\
3 & -12.92 & -11.09 & -27.24 & -36.99 \\
4 & -7.62 & -15.53 & -15.15 & -18.34 \\
\hline
\end{tabular}

one sulfuric acid and one DMA molecule are present in the cluster. In contrast to ammonia clusters, if the cluster contains more DMA molecules than acids, the proton from an $\mathrm{HSO}_{4}^{-}$is transferred to the extra DMA molecule, forming $\mathrm{SO}_{4}^{2-}$ even when only one sulfuric acid molecule is present in the cluster. However, it should be noted that only one $\mathrm{SO}_{4}^{2-}$ is formed, so for example in the $\left(\mathrm{H}_{2} \mathrm{SO}_{4}\right)_{2}\left(\left(\mathrm{CH}_{3}\right)_{2} \mathrm{NH}\right)_{4}$, cluster three DMA molecules are protonated instead of four. The number of protonated bases molecules for each cluster can be found on supplementary material Table S-5.1.

Table 3 summarizes the sulfuric acid addition Gibbs free energies $\left(\left(\mathrm{H}_{2} \mathrm{SO}_{4}\right)_{n-1}\left(\mathrm{NH}_{3} /\left(\mathrm{CH}_{3}\right)_{2} \mathrm{NH}\right)_{m}+\mathrm{H}_{2} \mathrm{SO}_{4} \diamond\right.$ $\left.\left(\mathrm{H}_{2} \mathrm{SO}_{4}\right)_{n}\left(\mathrm{NH}_{3} /\left(\mathrm{CH}_{3}\right)_{2} \mathrm{NH}\right)_{m}\right)$ and Table 4 the base addition energies $\left(\left(\mathrm{H}_{2} \mathrm{SO}_{4}\right)_{n}\left(\mathrm{NH}_{3} /\left(\mathrm{CH}_{3}\right)_{2} \mathrm{NH}\right)_{m-1}+\mathrm{NH}_{3} /\left(\mathrm{CH}_{3}\right)_{2} \mathrm{NH}\right.$ $\left.\rightarrow\left(\mathrm{H}_{2} \mathrm{SO}_{4}\right)_{n}\left(\mathrm{NH}_{3} /\left(\mathrm{CH}_{3}\right)_{2} \mathrm{NH}\right)_{m}\right)$ obtained in the present work (the formation free energies, enthalpies and entropies from monomers for all the clusters included in this work can be found in supplementary material S3.1).

The results agree in general with previous calculations for ammonia and DMA containing clusters (Loukonen et al., 2010; Kurtén, 2011; Nadykto et al., 2011). However, in some cases the differences are significant. In particular, this is observed for the addition energies recently published by Nadykto et al. (2011). According to the comment published by Kurtén (2011) regarding that work, the PW91PW91 method used in Nadykto et al. (2011) tends to underestimate the binding of sulfuric acid to clusters containing bases when compared with high level multistep methods such as G3,G2, G3MP2 and G2MP2. The B3RICC2 method used in the present work yields addition free energies close to those predicted by the high level multistep methods. So the differences between the current formation free energies and those presented by Nadykto et al. are most probably due to the dif- ferent method used in their work. These different methods also predict different structures for the most stable clusters, but further calculations have shown than the energy difference between different structures is usually relatively small $\left(2-3 \mathrm{kcal} \mathrm{mol}^{-1}\right)$. Similarly, some of the formation free energies given in Loukonen et al. (2010) are significantly lower (more negative) than those given here, mainly due to the use of fitted scaling factors which may overestimate the binding of some larger clusters (see Kurtén et al., 2011a for further discussion on this).

Using the Eqs. (3), (4) and these formation free energies, we have calculated the evaporation rate for all these clusters (Table 5). Figure 2 represents the evaporation of sulfuric acid and base from the cluster versus clusters sizes for different clusters compositions.

As can be seen in Fig. 2, for clusters containing just one base molecule, the evaporation of one sulfuric acid molecule will be preferred. The stabilizing effect of the single base molecule decreases as the number of sulfuric acid molecules increases in the cluster. Evaporation rates of clusters containing four sulfuric acid molecules and only one base molecule are fairly close to the evaporation rate of the sulfuric acid tetramer $\left(6.30 \times 10^{3} 1 \mathrm{~s}^{-1}, \mathrm{~S} 4.1\right.$ in supplementary material). As the number of base molecules grows, the evaporation of the base starts to be more important than the evaporation of the acid. Whenever there are more bases than acids in the clusters, the evaporation rate of the extra base molecules is high. For DMA - containing clusters, clusters with the same number of base and acid molecules are the most stable. In ammonia - containing clusters, clusters with one extra acid molecule are the most stable. The most stable and hence longest-lived cluster overall is $\left(\mathrm{H}_{2} \mathrm{SO}_{4}\right)_{2} \bullet\left(\left(\mathrm{CH}_{3}\right)_{2} \mathrm{NH}\right)_{2}$, for which the highest evaporation rate (evaporation of a DMA molecule) is $3.91 \times 10^{-6} 1 \mathrm{~s}^{-1}$. This is considerably smaller than the largest evaporation rate for both $\left(\mathrm{H}_{2} \mathrm{SO}_{4}\right)_{2} \bullet\left(\left(\mathrm{CH}_{3}\right)_{2} \mathrm{NH}\right)_{3}$ and $\left(\mathrm{H}_{2} \mathrm{SO}_{4}\right)_{3} \bullet\left(\left(\mathrm{CH}_{3}\right)_{2} \mathrm{NH}\right)_{2}$. The presence of these exceptionally stable clusters corresponding to deep local minima on the free energy surface indicates that the fission of larger clusters into such minima might in some cases be faster the evaporation of monomers. To determine whether this is the case, we have calculated cluster fission rates (non-monomer evaporation rates) for all possible pathways involving one of these really stable clusters as a daughter (product). Calculated evaporation/fission rates for these fragments are listed in the supplementary material (S4.2). Clusters containing two or more DMA molecules turn out to be the only ones where non-monomer evaporation (cluster fission) reactions are important. For all other clusters, evaporation of the acid or the base monomers is always preferred. Figure 3 shows most relevant non-monomer evaporation rates compared to the monomer evaporation rate for clusters containing from two to four DMA molecules. 
Table 4. Evaporation rates $\left(1 \mathrm{~s}^{-1}\right)$ for different clusters included in this work.

\begin{tabular}{|c|c|c|c|c|}
\hline & $\begin{array}{c}\text { Sulfuric acid } \\
\text { evaporation rate }\end{array}$ & $\begin{array}{c}\text { Ammonia evaporation } \\
\text { rate }\end{array}$ & $\begin{array}{c}\text { Sulfuric acid } \\
\text { evaporation rate }\end{array}$ & $\begin{array}{c}\text { DMA } \\
\text { Evaporation rate }\end{array}$ \\
\hline Sulfuric acid (n) & \multicolumn{2}{|c|}{1 Ammonia } & \multicolumn{2}{|c|}{$1 \mathrm{DMA}$} \\
\hline 1 & $3.24 \times 10^{4}$ & $3.24 \times 10^{4}$ & $5.94 \times 10^{-2}$ & $5.94 \times 10^{-2}$ \\
\hline 2 & $1.22 \times 10^{-2}$ & $3.27 \times 10^{-2}$ & $5.47 \times 10^{-5}$ & $2.20 \times 10^{-10}$ \\
\hline 3 & $3.83 \times 10^{2}$ & $7.30 \times 10^{-5}$ & 3.7 & $4.20 \times 10^{-15}$ \\
\hline \multirow[t]{2}{*}{4} & $7.97 \times 10^{3}$ & $9.91 \times 10^{-5}$ & $3.04 \times 10^{4}$ & $1.97 \times 10^{-14}$ \\
\hline & \multicolumn{2}{|c|}{2 Ammonia } & \multicolumn{2}{|c|}{2 DMA } \\
\hline 1 & $7.43 \times 10^{-3}$ & $4.11 \times 10^{6}$ & $4.10 \times 10^{-8}$ & $3.76 \times 10^{6}$ \\
\hline 2 & $4.86 \times 10^{-6}$ & $1.83 \times 10^{3}$ & $5.88 \times 10^{-17}$ & $3.91 \times 10^{-6}$ \\
\hline 3 & $1.73 \times 10^{-2}$ & $8.99 \times 10^{-2}$ & 90.8 & $9.31 \times 10^{-5}$ \\
\hline \multirow[t]{2}{*}{4} & 87.4 & $1.05 \times 10^{-3}$ & $5.32 \times 10^{-2}$ & $1.59 \times 10^{-10}$ \\
\hline & \multicolumn{2}{|c|}{3 Ammonia } & \multicolumn{2}{|c|}{3 DMA } \\
\hline 1 & $1.42 \times 10^{-6}$ & $5.93 \times 10^{9}$ & $4.24 \times 10^{-13}$ & $5.10 \times 10^{6}$ \\
\hline 2 & $3.27 \times 10^{-9}$ & $4.40 \times 10^{6}$ & $3.41 \times 10^{-18}$ & $2.89 \times 10^{5}$ \\
\hline 3 & $3.27 \times 10^{-9}$ & 0.9 & $1.44 \times 10^{-10}$ & $4.48 \times 10^{-7}$ \\
\hline \multirow[t]{2}{*}{4} & 0.5 & $5.45 \times 10^{-3}$ & 0.1 & $9.03 \times 10^{-7}$ \\
\hline & \multicolumn{2}{|c|}{4 Ammonia } & \multicolumn{2}{|c|}{4 DMA } \\
\hline 1 & $1.70 \times 10^{-10}$ & $5.30 \times 10^{8}$ & $2.11 \times 10^{-15}$ & $6.10 \times 10^{7}$ \\
\hline 2 & $8.03 \times 10^{-10}$ & $1.42 \times 10^{8}$ & $4.27 \times 10^{-20}$ & $7.49 \times 10^{5}$ \\
\hline 3 & $2.20 \times 10^{-11}$ & $1.01 \times 10^{6}$ & $7.17 \times 10^{-15}$ & 36.9 \\
\hline 4 & $2.35 \times 10^{-5}$ & 49.8 & $8.19 \times 10^{-7}$ & $2.72 \times 10^{-4}$ \\
\hline
\end{tabular}
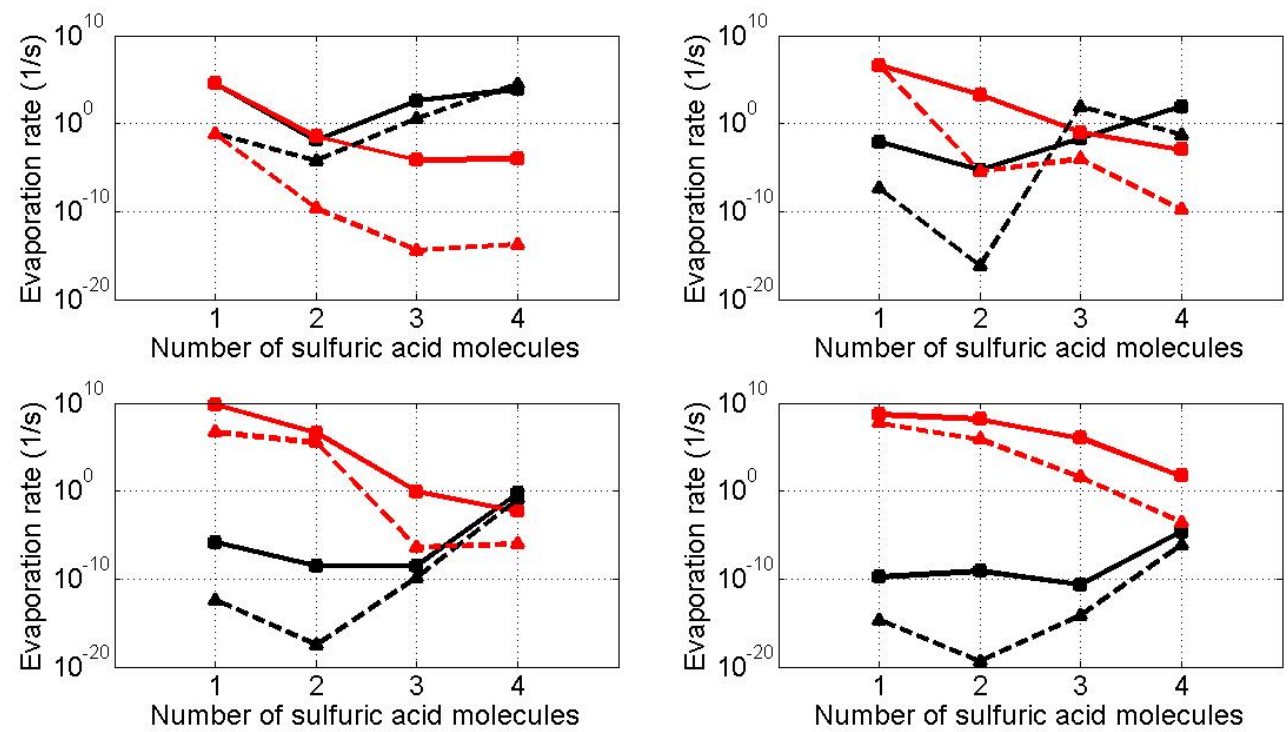

Fig. 2. Evaporation rates of acid (black lines) and base molecules (red lines) from ammonia (solid lines) and DMA (dashed lines) containing clusters. The top left, top right, bottom left, and bottom right panels give the results for 1, 2, 3, and 4 base containing clusters, respectively. 

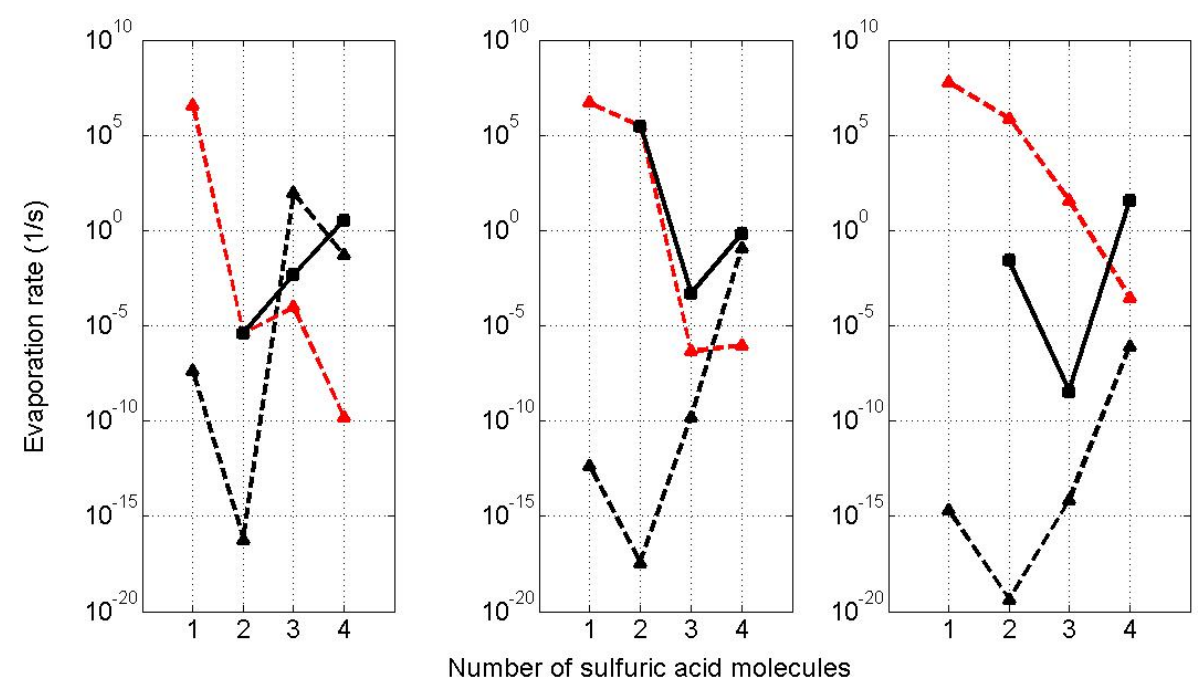

Fig. 3. Evaporation and fission (non-monomer evaporation) rates from DMA / $\mathrm{H}_{2} \mathrm{SO}_{4}$ clusters. Left panel: clusters with two DMA molecules. Middle panel: clusters with three DMA molecules. Right panel: clusters with four DMA molecules. Red dashed lines are the evaporation of DMA from the cluster, black dashed lines are the evaporation of sulfuric acid from the cluster, and solid black lines are the cluster fission reactions leading to the formation of the most stable daughter cluster $\left(\left(\mathrm{H}_{2} \mathrm{SO}_{4}\right)_{2} \bullet\left(\mathrm{CH}_{3}\right)_{2} \mathrm{NH}\right.$ for fission of two DMA clusters and $\left(\mathrm{H}_{2} \mathrm{SO}_{4}\right)_{2} \bullet\left(\left(\mathrm{CH}_{3}\right)_{2} \mathrm{NH}\right)_{2}$ for fission of three and four DMA clusters).

Table 5. Gibbs free energy for the reaction $\left(\left(\mathrm{H}_{2} \mathrm{SO}_{4}\right)_{n}\left(\mathrm{NH}_{3} /\right.\right.$ $\left.\left(\mathrm{CH}_{3}\right)_{2} \mathrm{NH}\right)_{m-1}+\mathrm{NH}_{3} /\left(\mathrm{CH}_{3}\right)_{2} \mathrm{NH} \rightarrow\left(\mathrm{H}_{2} \mathrm{SO}_{4}\right)_{n}$ $\left.\left(\mathrm{NH}_{3} /\left(\mathrm{CH}_{3}\right)_{2} \mathrm{NH}\right)_{m}\right)$ in kcal mol${ }^{-1}$ at $298.15 \mathrm{~K}$.

\begin{tabular}{lcccc}
\hline \multicolumn{5}{c}{ (m) ammonia } \\
\hline Sulfuric acid (n) & 1 & 2 & 3 & 4 \\
\hline 1 & -7.61 & -4.82 & -0.57 & -2.05 \\
2 & -15.93 & -9.50 & -4.93 & -2.91 \\
3 & -19.64 & -15.46 & -14.13 & -5.90 \\
4 & -19.53 & -18.16 & -17.21 & -11.83 \\
\hline
\end{tabular}

(m) DMA

\begin{tabular}{lcccc}
\hline Sulfuric acid (n) & 1 & 2 & 3 & 4 \\
\hline 1 & -15.40 & -4.89 & -4.79 & -3.38 \\
2 & -26.99 & -21.29 & -6.53 & -6.02 \\
3 & -33.50 & -19.46 & -22.68 & -15.77 \\
4 & -32.64 & -27.37 & -22.30 & -18.96 \\
\hline
\end{tabular}

In the case of two DMA clusters, we can see that cluster fission (non-monomer evaporation) is relevant when we have four sulfuric acid molecules in the cluster. The $\left(\mathrm{H}_{2} \mathrm{SO}_{4}\right)_{4} \bullet\left(\left(\mathrm{CH}_{3}\right)_{2} \mathrm{NH}\right)_{2} \rightarrow 2\left(\mathrm{H}_{2} \mathrm{SO}_{4}\right)_{2} \bullet\left(\mathrm{CH}_{3}\right)_{2} \mathrm{NH}$ fission rate is around two orders of magnitude larger than evaporation of one sulfuric acid molecule, so the cluster lifetime will be determined by that process rather that by the evaporation of sulfuric acid. Our results indicate (Fig. 3) that the evaporation rate of sulfuric acid molecule from $\left(\mathrm{H}_{2} \mathrm{SO}_{4}\right)_{3} \bullet\left(\left(\mathrm{CH}_{3}\right)_{2} \mathrm{NH}\right)_{2}$ cluster is relatively
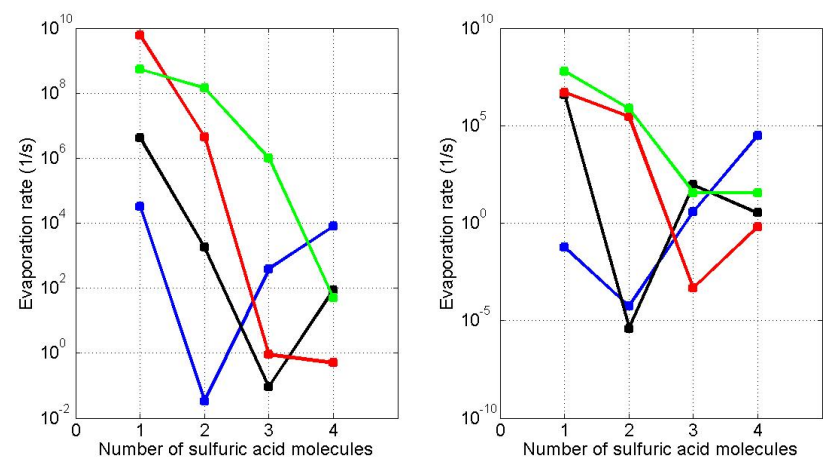

Fig. 4. Evaporation rates of different clusters versus number of sulfuric acid molecules in the cluster. The blue, black, red, and green lines represent clusters containing one, two, three, and four base molecules, respectively. The left panel is for ammonia clusters, while the right for those containing DMA.

high compared to the one for $\left(\mathrm{H}_{2} \mathrm{SO}_{4}\right)_{4} \bullet\left(\left(\mathrm{CH}_{3}\right)_{2} \mathrm{NH}\right)_{2}$ or $\left(\mathrm{H}_{2} \mathrm{SO}_{4}\right)_{4} \bullet\left(\mathrm{NH}_{3}\right)_{2}$ (Fig. 2). The reason for this high sulfuric acid evaporation rate is that the resulting daughter cluster $\left(\left(\mathrm{H}_{2} \mathrm{SO}_{4}\right)_{2} \bullet\left(\left(\mathrm{CH}_{3}\right)_{2} \mathrm{NH}\right)_{2}\right)$ is much more stable than the daughter clusters produced from $\left(\mathrm{H}_{2} \mathrm{SO}_{4}\right)_{4} \bullet\left(\left(\mathrm{CH}_{3}\right)_{2} \mathrm{NH}\right)_{2}$ or $\left(\mathrm{H}_{2} \mathrm{SO}_{4}\right)_{4} \bullet\left(\mathrm{NH}_{3}\right)_{2}$ clusters.

For clusters containing three DMA molecules, the main daughter cluster is $\left(\mathrm{H}_{2} \mathrm{SO}_{4}\right)_{2} \bullet\left(\left(\mathrm{CH}_{3}\right)_{2} \mathrm{NH}\right)_{2}$ instead of $\left(\mathrm{H}_{2} \mathrm{SO}_{4}\right)_{2} \bullet\left(\left(\mathrm{CH}_{3}\right)_{2} \mathrm{NH}\right)$. As can be seen from Fig. 3, the most important fission process (in terms of lifetime of the cluster) is $\left(\mathrm{H}_{2} \mathrm{SO}_{4}\right)_{3} \bullet\left(\left(\mathrm{CH}_{3}\right)_{2} \mathrm{NH}\right)_{3} \rightarrow\left(\mathrm{H}_{2} \mathrm{SO}_{4}\right)_{2} \bullet\left(\left(\mathrm{CH}_{3}\right)_{2} \mathrm{NH}\right)_{2}+$ $\mathrm{H}_{2} \mathrm{SO}_{4} \bullet\left(\mathrm{CH}_{3}\right)_{2} \mathrm{NH}$. The rate of this process is two orders of magnitude larger than the evaporation of a sulfuric 


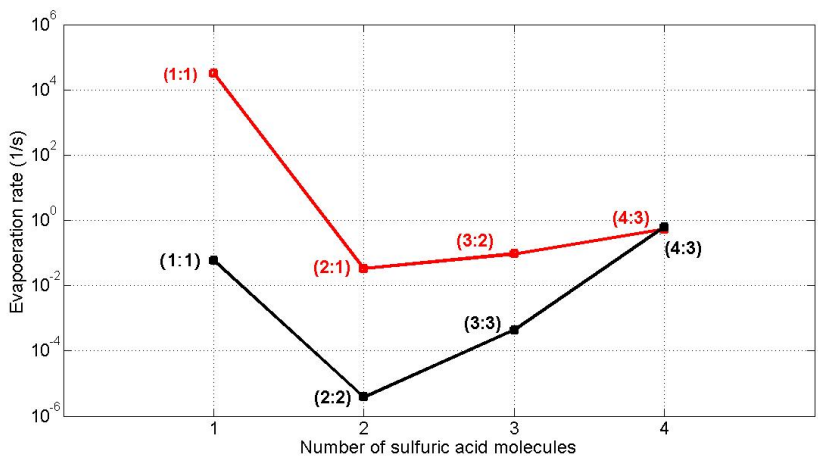

Fig. 5. Evaporation rates for the most stable clusters independently of the number of bases in it including non-monomer evaporation, composition of each cluster is indicated in parenthesis (acid:base), black line correspond to DMA containing clusters and red line to ammonia containing clusters.

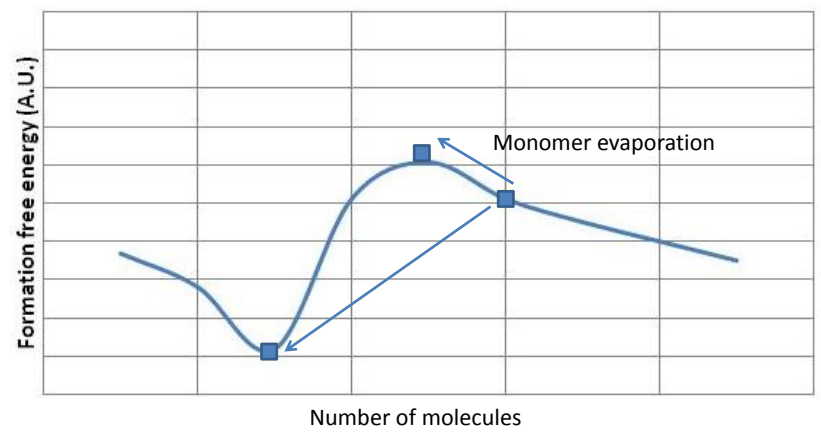

Fig. 6. Schematic representation of the effect of cluster fragmentation in over-critical clusters

acid monomer. $\left(\mathrm{H}_{2} \mathrm{SO}_{4}\right)_{4} \bullet\left(\left(\mathrm{CH}_{3}\right)_{2} \mathrm{NH}\right)_{3}$ breaking into $\left(\mathrm{H}_{2} \mathrm{SO}_{4}\right)_{2} \bullet\left(\left(\mathrm{CH}_{3}\right)_{2} \mathrm{NH}\right)_{1}$ and $\left(\mathrm{H}_{2} \mathrm{SO}_{4}\right)_{2} \bullet\left(\left(\mathrm{CH}_{3}\right)_{2} \mathrm{NH}\right)_{2}$ is also slightly preferred to the loss of one sulfuric acid molecule, but the difference between these two rates is not as large as in the trimer.

Of the clusters containing four DMA molecules, cluster fission plays the largest role for the $\left(\mathrm{H}_{2} \mathrm{SO}_{4}\right)_{4} \bullet\left(\left(\mathrm{CH}_{3}\right)_{2} \mathrm{NH}\right)_{4}$ cluster. $\quad$ The DMA evaporation rate for this cluster is $2.72 \times 10^{-4} \mathrm{~s}^{-1}$, but the fission rate of the cluster into two $\left(\mathrm{H}_{2} \mathrm{SO}_{4}\right)_{2} \bullet\left(\left(\mathrm{CH}_{3}\right)_{2} \mathrm{NH}\right)_{2}$ daughters is $35.29 \mathrm{~s}^{-1}$, around six orders of magnitude higher. This is understandable since this reaction leads to not one but two $\left(\mathrm{H}_{2} \mathrm{SO}_{4}\right)_{2} \bullet\left(\left(\mathrm{CH}_{3}\right)_{2} \mathrm{NH}\right)_{2}$ products which are, by far, the most stable clusters among all those studied.

To illustrate the overall stability of the different cluster, we have plotted the largest evaporation/fission rate for each cluster in Fig. 4.

The most stable ammonia - containing clusters are $\left(\mathrm{H}_{2} \mathrm{SO}_{4}\right)_{2} \bullet \mathrm{NH}_{3},\left(\mathrm{H}_{2} \mathrm{SO}_{4}\right)_{3} \bullet\left(\mathrm{NH}_{3}\right)_{2}$ and $\left(\mathrm{H}_{2} \mathrm{SO}_{4}\right)_{4} \bullet\left(\mathrm{NH}_{3}\right)_{3}$, although the stability of $\left(\mathrm{H}_{2} \mathrm{SO}_{4}\right)_{3} \bullet\left(\mathrm{NH}_{3}\right)_{3}$ is rather close to $\left(\mathrm{H}_{2} \mathrm{SO}_{4}\right)_{4} \bullet\left(\mathrm{NH}_{3}\right)_{3}$. The most stable clusters seem to have one sulfuric acid molecule more than ammo- nia molecules in it. Overall, the most stable ammonia cluster is $\left(\mathrm{H}_{2} \mathrm{SO}_{4}\right)_{2} \bullet \mathrm{NH}_{3}$. This cluster is a local minimum within the cluster set studied, although it should be noted that evaporation rates for all these cluster are relatively close. In other words, the local minimum is not very deep for ammonia-containing clusters. In the case of DMA - containing clusters, $\left(\mathrm{H}_{2} \mathrm{SO}_{4}\right)_{3} \bullet\left(\left(\mathrm{CH}_{3}\right)_{2} \mathrm{NH}\right)_{3}$, $\mathrm{H}_{2} \mathrm{SO}_{4} \bullet\left(\mathrm{CH}_{3}\right)_{2} \mathrm{NH},\left(\mathrm{H}_{2} \mathrm{SO}_{4}\right)_{2} \bullet\left(\left(\mathrm{CH}_{3}\right)_{2} \mathrm{NH}\right)$ and especially $\left(\mathrm{H}_{2} \mathrm{SO}_{4}\right)_{2} \bullet\left(\left(\mathrm{CH}_{3}\right)_{2} \mathrm{NH}\right)_{2}$ clusters are quite stable. The most stable clusters contain as many DMA as sulfuric acid molecules. $\left(\mathrm{H}_{2} \mathrm{SO}_{4}\right)_{2} \bullet\left(\left(\mathrm{CH}_{3}\right)_{2} \mathrm{NH}\right)_{2}$ is clearly more stable than any other cluster, in other words the local minimum in the free energy surface is quite deep.

To compare ammonia and DMA containing clusters we can plot the most stable cluster versus the number of sulfuric acid molecules in the cluster independently of the number for bases (Fig. 5).

Comparing the stability of ammonia clusters versus DMA clusters, we can see how DMA clearly forms stable clusters containing up to three sulfuric acid molecules, but when we reach four sulfuric acid molecules clusters, the stability of DMA cluster is about the same as the stability of ammonia clusters. This is mainly due to the exceptionally high stability of $\left(\mathrm{H}_{2} \mathrm{SO}_{4}\right)_{2} \bullet\left(\left(\mathrm{CH}_{3}\right)_{2} \mathrm{NH}\right)_{2}$, which makes the fission of $\left(\mathrm{H}_{2} \mathrm{SO}_{4}\right)_{4} \bullet\left(\left(\mathrm{CH}_{3}\right)_{2} \mathrm{NH}\right)_{4}$ into two identical parts a very favorable process.

The presence of this deep minimum for DMA clusters has several implications. Vehkamäki et al. (2011) have shown how the first nucleation theorem is not straight forwardly applicable to systems with a local minimum. This is the case for sulfuric acid nucleation in the presence of ammonia and especially DMA. Consequently, the slope of the logarithm of the sulfuric acid concentration versus the logarithm of nucleation rate may not correspond to the number of sulfuric acid molecules in the critical cluster (free energy maximum or saddle point) if any of these bases are present. As discussed in Vehkamäki et al. (2011), in the presence of local minima cluster-cluster collisions (coagulation) have to be accounted for even for the smallest clusters. Similarly, also cluster fission (non-monomer evaporation) has to be accounted for. In the derivation of the nucleation theorem, only monomermonomer collisions/evaporations have been considered. This result is crucial, since ammonia and DMA clusters are probably present in all atmospheric and laboratory measurements of new particle formation (Sipilä et al., 2010; Petäjä et al., 2011), and often the nucleation theorem is used to estimate the number of molecules in the critical cluster in those measurements.

We have shown how the fragmentation of a cluster into non-monomer smaller clusters is important in the sulfuric acid - DMA system. Even if some cluster is beyond the critical cluster with respect to monomer evaporation (and should, in theory, spontaneously become a liquid drop), it may still be unstable with respect to fission back into the local minimum. This is illustrated schematically in Fig. 6. 


\section{Conclusions}

We have tested multiple quantum chemistry methods to calculate formation free energies of clusters containing sulfuric acid and base molecules. The combination of B3LYP/CBSB7 optimized geometries and frequency calculations with an RI-CC2/aug-cc-pVTZ single point energy calculation have proven to produce reliable formation free energies (as verified by comparison to higher level methods), but at an affordable computational cost. We have used the formation free energies obtained with this approach to calculate the evaporation rates of sulfuric acid clusters containing either ammonia or DMA molecules, with up to four acids and bases. We have found that monomer evaporation rates alone are not enough to determine the overall stability of DMA containing clusters. Comparing the stability of clusters with ammonia or DMA, we have found that DMA can form very stable clusters with sulfuric acid, which agrees with our previous work (Kurtén et al., 2008; Loukonen et al., 2010). On the other hand, we have shown how the presence of those extremely stable clusters can make growth to larger sizes unfavourable due to non-monomer evaporation (cluster fission). According to these results, DMA will probably combine with sulfuric acid to form three- and four- molecule clusters, but may in many conditions probably need a third component (or a high concentration of $\mathrm{H}_{2} \mathrm{SO}_{4}$ or DMA) to grow to larger sizes.

\section{Supplementary material related to this article is available online at: http://www.atmos-chem-phys.net/12/225/2012/ acp-12-225-2012-supplement.zip.}

Acknowledgements. We thank Professor Torsten Berndt for inspiration and useful discussions. This work was supported by the projects,FP7-ATMNUCLE project No. 227463 (ERC Advanced Grant), Academy of Finland LASTU program project number 135054, FP7-MOCAPAF project No 257360 (ERC Starting grant), and National Science Foundation Grant No. OISE- 0853294. The authors thank the Scientific Computing Center (CSC) in Espoo, Finland, for the computing time.

Edited by: A. Hofzumahaus

\section{References}

Ahlrichs, R., Bär, M., Häser, J., Horn, H., and Kölmel C.: Electronic structure calculations on workstation computers: the program system TURBOMOLE, Chem. Phys. Lett., 162, 165-169, 1989.

Baboul, A. G., Curtiss, L. A., Redfern, P. C., and Raghavachari, K.: Gaussian-3 theory using density functional geometries and zero-point energies, J. Chem. Phys., 110, 7650-7658, 1999

Baker, M. B. and Peter, T.,: Small-scale cloud processes and climate, Nature, 45, 299-230, 2008.
Chapman, S. and Cowling, T. G.: The mathematical theory of nonuniform gases, University Press, Cambridge, 1970.

Cohen, R. E., Mehl, M. J., and Papaconstantopoulos, D. A.: Tightbinding total energy method for transition and noble-metals, Phys. Rev. B, 50, 14694, 1994.

Curtiss, L. A., Redfern, P. C., and Raghavachari, K.: Gaussian-4 theory, J. Chem. Phys., 126, 084108, 2007.

Dewar, M. J. S., Zoebisch, E. G., Healy, E. F., and Stewart, J. J. P. Development and use of quantum mechanical molecular models. 76. AM1: a new general purpose quantum mechanical molecular model, J. Am. Chem. Soc., 107, 3902-3909, 1985.

Dunning Jr., T. H., Peterson, K. A., and Wilson, A. K.: Gaussian basis sets for use in correlated molecular calculations. X. The atoms aluminum through argon revisited, J. Chem. Phys., 114, 9244-9253, 2001.

Friedlander, S. K.: Smoke, dust and haze, John Wiley \& Sons, New York, 1977.

Frisch, M. J., Trucks, G. W., Schlegel, H. B., Scuseria, G. E., Robb, M. A., Cheeseman, J. R., Scalmani, G., Barone, V., Mennucci, B., Petersson, G. A., Nakatsuji, H., Caricato, M., Li, X., Hratchian, H. P., Izmaylov, A. F., Bloino, J., Zheng, G., Sonnenberg, J. L., Hada, M., Ehara, M., Toyota, K., Fukuda, R., Hasegawa, J., Ishida, M., Nakajima, T., Honda, Y., Kitao, O., Nakai, H., Vreven, T., Montgomery Jr., J. A., Peralta, J. E., Ogliaro, F., Bearpark, M., Heyd, J. J., Brothers, E., Kudin, K. N., Staroverov, V. N., Kobayashi, R., Normand, J., Raghavachari, K., Rendell, A., Burant, J. C., Iyengar, S. S., Tomasi, J., Cossi, M., Rega, N., Millam, J. M., Klene, M., Knox, J. E., Cross, J. B., Bakken, V., Adamo, C., Jaramillo, J.,Gomperts, R., Stratmann, R. E., Yazyev, O., Austin, A. J., Cammi, R., Pomelli, C., Ochterski, J. W., Martin, R. L., Morokuma, K., Zakrzewski, V. G., Voth, G. A., Salvador, P., Dannenberg, J. J., Dapprich, S., Daniels, A. D., Farkas, Ö ., Foresman, J. B., Ortiz, J. V., Cioslowski, J., and Fox, D. J.: Gaussian 09, Revision B01, Gaussian, Inc., Wallingford CT, 2009.

Ge, X., Wexler, A. S., and Clegg, S. L.: Atmospheric amines-PartI. A review, Atmos. Environ., 45, 524-546, 2011.

Ge, X., Wexler, A. S., and Clegg, S. L.: Atmospheric amines-PartII. Thermodynamic properties and gas/particle partitioning, Atmos. Environ., 45, 561-577, 2011.

Hättig, C. and Weigend, F.: CC2 excitation energy calculations on large molecules using the resolution of the identity approximation, J. Chem. Phys., 113, 5154-5161, 2000.

IPCC, The Intergovernmental Panel on Climate Change: Climate Change 2007: The Physical Science Basis. Cambridge University Press, New York, 2007.

Junninen, H., Ehn, M., Petäjä, T., Luosujärvi, L., Kotiaho, T., Kostiainen, R., Rohner, U., Gonin, M., Fuhrer, K., Kulmala, M., and Worsnop, D. R.: A high-resolution mass spectrometer to measure atmospheric ion composition, Atmos. Meas. Tech., 3, 10391053, doi:10.5194/amt-3-1039-2010, 2010.

Kazil, J., Stier, P., Zhang, K., Quaas, J., Kinne, S., ODonnell, D., Rast, S., Esch, M., Ferrachat, S., Lohmann, U., and Feichter, J.: Aerosol nucleation and its role for clouds and Earths radiative forcing in the aerosol-climate model ECHAM5-HAM, Atmos. Chem. Phys., 10, 10733-10752, doi:10.5194/acp-1010733-2010, 2010.

Kuang, C., McMurry, P. H., McCormick, A.V., Eisele, F.L.: Dependence of nucleation rates on sulfuric acid vapor concentration in 
diverse atmospheric locations, J. Geophys. Res., 113, D10209, doi:10.1029/2007JD009253, 2008.

Kulmala, M.: Dynamical atmospheric cluster model, Atmos. Res., 98, 201-206, 2010.

Kulmala, M., Vehkamäki, H., Petäjä, T., Dal Maso, M., Lauri, A., Kerminen V.-M., Birmili, W., and McMurry, P. H.: Formation and growth rates of ultrafine atmospheric particles: a review of observations, J. Aerosol. Sci., 35:143-176, 2004.

Kulmala, M., Riipinen, I., Sipilä, M., Manninen, H. E., Petäjä, T., Junninen, H., Dal Maso, M., Mordas, G., Mirme, A., Vana, M., Hirsikko, A., Laakso, L., Harrison, R.M., Hanson, I., Leung, C., Lehtinen, K. E. J., Kerminen, V.-M.:Toward direct measurement of atmospheric nucleation, Science, 318, 89-92, 2007.

Kurtén, T., Loukonen, V., Vehkamäki, H., and Kulmala, M.: Amines are likely to enhance neutral and ion-induced sulfuric acid-water nucleation in the atmosphere more effectively than 30 ammonia, Atmos. Chem. Phys., 8, 4095-4103, doi:10.5194/acp8-4095-2008, 2008.

Kurtén, T. and Vehkamäki, H.: Investigating atmospheric sulfuric acid-water-ammonia particle formation using quantum chemistry, Adv. Quantum Chem., 55, 407-427, 2008.

Kurtén, T.: A Comment on Nadytko et al.: Amines in the Earth's Atmosphere: A Density Functional Theory Study of the Thermochemistry of Pre-Nucleation Cluster, Entropy 2011, 13, 554-569, Entropy, 13, 912-923, 2011.

Kurtén, T., Kuang, C. A., Gomez, P., McMurry, P. H., Vehkamäki, H., Ortega, I. K., Noppel, M., and Kulmala, M.: The role of cluster energy non-accommodation in atmospheric sulfuric acid nucleation, J. Chem. Phys., 132, 024304, doi:10.1063/1.3291213, 2010.

Kurtén, T., Petäjä, T., Smith, J., Ortega, I. K., Sipilä, M., Junninen, H., Ehn, M., Vehkamäki, H., Mauldin, L., Worsnop, D. R., and Kulmala, M.: The effect of $\mathrm{H}_{2} \mathrm{SO}_{4}$ - amine clustering on chemical ionization mass spectrometry (CIMS) measurements of gas-phase sulfuric acid, Atmos. Chem. Phys., 11, 3007-3019, doi:10.5194/acp-11-3007-2011, 2011.

Loukonen, V., Kurtén, T., Ortega, I. K., Vehkamäki, H., Padua, A. A. H., Sellegri, K., and Kulmala, M.: Enhancing effect of dimethylamine in sulfuric acid nucleation in the presence of water - a computational study, Atmos. Chem. Phys., 10, 49614974, doi:10.5194/acp-10-4961-2010, 2010.

Lovejoy, E. R., Curtius, J., and Froyd, K. D.: Atmospheric ioninduced nucleation of sulfuric acid and water, J. Geophys. Res., 109, D08204, doi:10.1029/2003JD004460, 2004.

Lozynski, M., Rusinska-Roszak, D., and Mack, H-G.: Hydrogen bonding and density functional calculations: the B3LYP approach as the shortest way to MP2 results, J. Phys. Chem. A, 102, 2899-2903, 1998.

McGrath, M. J., Olenius, T., Ortega, I. K., Loukonen, V., Paasonen, P., Kurtén, T., Kulmala, M., and Vehkamäki, H.: Atmospheric Cluster Dynamics Code: a flexible method for solution of the birth-death equations, Atmos. Chem. Phys. Discuss., 11, $25263-$ 25295, doi:10.5194/acpd-11-25263-2011, 2011.

Merikanto, J., Spracklen, D. V., Mann, G. W., Pickering, S. J., and Carslaw, K. S.: Impact of nucleation on global CCN, Atmos. Chem. Phys., 9, 8601-8616, doi:10.5194/acp-9-8601-2009, 2009.
Montgomery, J. A., Frisch, M. J., Ochterski, J. W., Petersson, G. A.: A complete basis set model chemistry. VI. Use of density functional geometries and frequencies, J. Chem. Phys., 110, 2822 2827, 1999.

Montgomery, J. A., Frisch, M. J., Ochterski, J. W., and Petersson, G. A.: A complete basis set model chemistry. VII, Use of the minimum population localization method, J. Chem. Phys., 112, 6532-6542, 2000.

Nadykto, A. B., Al Natsheh, A., Yu, F. Q., Mikkelsen, K. V., and Herb, J.: Computational quantum chemistry: A new approach to atmospheric nucleation, Adv. Quantum Chem., 55, 449-478, 2008.

Nadykto, A. B., Yu, F. Q., Jakovleva, M. V., Herb, J., and Xu, Y. S.: Amines in the Earth's atmosphere: a density functional theory study of the thermochemistry of pre-nucleation clusters, Entropy, 13, 554-569, 2011.

Nel, A.: Air pollution-related illness: Effects of particles, Science, 308, 804-806, 2005.

Ortega, I. K., Kurt en, T., Vehkamäki, H., and Kulmala, M.: The role of ammonia in sulfuric acid ion induced nucleation, Atmos. Chem. Phys., 8, 2859-2867, doi:10.5194/acp-8-2859-2008, 2008.

Petäjä, T., Sipilä, M., Paasonen, P., Nieminen, T., Kurtén, T., Ortega, I. K., Stratmann, S., Vehkamäki, H., Berndt, T., Kulmala, M.: Experimental observation of strongly bound dimers of sulphuric acid nucleating in the atmosphere, Phys. Rev. Lett., 106, 228302, doi:10.1103/PhysRevLett.106.228302, 2011.

Pope, C. A. and Dockery, D. W.: Health effects of fine particulate air pollution: Lines that connect, J. Air \& Waste Manage. Assoc., 56, 709-742, 2006.

Sihto, S.-L., Kulmala, M., Kerminen, V.-M., Dal Maso, M., Petäjä , T., Riipinen, I., Korhonen, H., Arnold, F., Janson, R., Boy, M., Laaksonen, A., and Lehtinen, K. E. J.: Atmospheric sulphuric acid and aerosol formation: implications from atmospheric measurements for nucleation and early growth mechanisms, Atmos. Chem. Phys., 6, 4079-4091, doi:10.5194/acp-64079-2006, 2006.

Sipilä, M., Berndt, T., Petäjä, T., Brus, D., Vanhanen, J., Stratmann, F., Patokoski, J., Mauldin, R. L., Hyvärinen, A.-P., Lihavainen, H., and Kulmala, M.: The role of sulfuric acid in atmospheric nucleation, Science, 327, 1243-1246, 2010.

Spracklen, D. V., Carslaw, K. S., Kulmala, M., Kerminen, V.-M., Sihto, S. L., Riipinen, I., Merikanto, J., Mann, G. W., Chipperfield, M. P., Wiedensohler, A., Birmilli, W., and Lihavainen, H.: contribution of particle formation to global cloud condensation nuclei concentrations, Geophys. Res. Lett., 35, L06808, doi:10.1029/2007GL033038, 2008.

Stewart, J. J. P.: Optimization of parameters for semiempirical methods.1 Method, J. Comput. Chem., 10, 209-220, 1989.

Stewart, J. J. P.: Optimization of Parameters for Semiempirical Methods V: Modification of NDDO Approximations and Application to 70 Elements, J. Mol. Modeling, 13, 1173-1213, 2007.

Vehkamäki, H., McGrath, M. J., Kurtén, T., Julin, J., Lehtinen, K. E. J., and Kulmala, M.: Rethinking the application of the first nucleation theorem to atmospheric particle formation, J. Chem. Phys., in press, 2011. 